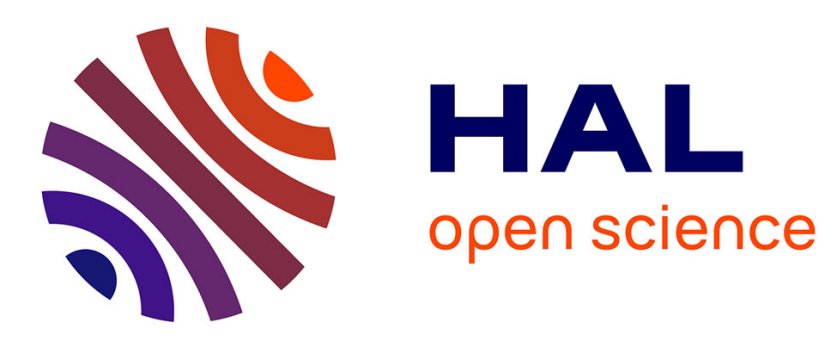

\title{
LF Excess Noise of AlGaAs/GaAs and AlGaAs/InGaAs/GaAs HEMTs
}

N. Saysset, C. Maneux, N. Labat, A. Touboul, Y. Danto, J. Dumas

\section{To cite this version:}

N. Saysset, C. Maneux, N. Labat, A. Touboul, Y. Danto, et al.. LF Excess Noise of AlGaAs/GaAs and AlGaAs/InGaAs/GaAs HEMTs. Journal de Physique III, 1995, 5 (5), pp.509-517. 10.1051/jp3:1995134 . jpa-00249327

\section{HAL Id: jpa-00249327 https://hal.science/jpa-00249327}

Submitted on 1 Jan 1995

HAL is a multi-disciplinary open access archive for the deposit and dissemination of scientific research documents, whether they are published or not. The documents may come from teaching and research institutions in France or abroad, or from public or private research centers.
L'archive ouverte pluridisciplinaire HAL, est destinée au dépôt et à la diffusion de documents scientifiques de niveau recherche, publiés ou non, émanant des établissements d'enseignement et de recherche français ou étrangers, des laboratoires publics ou privés. 
Classification

Physics Abstracts

$72.70-72.20 \mathrm{~J}-72.80 \mathrm{E}-71.55$

\title{
LF Excess Noise Analysis of AlGaAs/GaAs and AlGaAs/InGaAs/ GaAs HEMTs
}

\author{
N. Saysset $\left({ }^{1}\right)$, C. Maneux $\left({ }^{1}\right)$, N. Labat $\left({ }^{1}\right)$, A. Touboul $\left({ }^{1}\right)$, Y. Danto $\left({ }^{1}\right)$ and J.M. Dumas $\left({ }^{2}\right)$ \\ ( ${ }^{1}$ IXL, URA 846-CNRS, University Bordeaux I, 351 Cours de la Libération, 33405 Talence, \\ France \\ ( $\left.{ }^{2}\right)$ ENSIL, 83 rue d'Isle, 87000 Limoges, France
}

(Received 8 July 1994, revised 14 December 1994, accepted 26 January 1995)

\begin{abstract}
The quality of AlGaAs/GaAs/buffer layer on GaAs HEMTs and of AlGaAs/ InGaAs/GaAs HEMTs is studied on the basis of technological parameter influence: Al molefraction in the n-AlGaAs layer, type of the buffer layer (p- or n- doped GaAs or AlGaAs), In molefraction in pseudomorphic structures. From the LF drain noise behaviour versus gate and drain biases and temperature ( $90 \mathrm{~K}$ to $300 \mathrm{~K})$, pseudomorphic devices are found to present lower drain current noise and less G-R contributions when compared to conventional HEMTs. This difference might result from a lower deep level concentration.
\end{abstract}

\section{Introduction}

The parasitic effects in conventional HEMTs are related to deep levels which affect the functional operation of both discrete devices and integrated circuits. These anomalies mainly appear as frequency and temperature dependent current or voltage transients [1]. The location of the contributing traps depends on the operating mode of the devices. They are related to the manufacturing processes and to the electrical and physical properties of each layer and of their interfaces. The influence of these levels can be characterised by $L F$ noise analysis through the $1 / f$ noise level and the possible G-R noise contributions appearing in the spectra.

The dominant trap level in conventional AlGaAs/GaAs HEMTs has been identified as the DX center which lies between 0.5 and $0.4 \mathrm{eV}$ below the conduction band [2,3]. It has been demonstrated that a low $\mathrm{Al}$ molefraction in $\mathrm{n}$-AlGaAs must be achieved to minimize the $\mathrm{DX}$ traps related effects. A low molefraction of $\mathrm{Al}$ also reduces the heterojunction conduction band discontinuity. It appears difficult to preserve the two dimensional electron gas density while reducing the DX level influence on the AlGaAs/GaAs HEMT operation.

The quantum well pseudomorphic AlGaAs/InGaAs structure maintains a significant potential barrier while reducing the Al molefraction in the n-AlGaAs layer. In the AlGaAs/GaAs system, an $\mathrm{Al}$ molefraction greater than 0.22 is required to provide a significant conduction band offset $\left(\Delta E_{c}\right)$ while in the AlGaAs/InGaAs system, an Al molefraction of only 0.15 is 
Table I. - Technological characteristics of devices under test.

\begin{tabular}{|c|c|c|c|c|c|}
\hline Device & $\begin{array}{c}\mathrm{n}+\text { GaAs cap layer } \\
\text { thickness }(\AA)\end{array}$ & $\begin{array}{c}\text { AlGaAs layer } \\
\text { thickness }(\AA)\end{array}$ & $\begin{array}{c}\text { InGaAs layer } \\
\text { thickness }(\AA)\end{array}$ & $\begin{array}{c}\text { GaAs buffer } \\
\text { dopant type }\end{array}$ & $\begin{array}{c}\text { AlGaAs buffer } \\
\text { thickness }(\AA)\end{array}$ \\
\hline A & 300 & 400 & - & $\mathrm{p}-$ & 1000 \\
\hline B & 300 & 500 & - & $\mathrm{p}-$ & - \\
\hline C & 500 & 480 & - & $\mathrm{n}-$ & - \\
\hline D & 300 & 450 & 150 & $\mathrm{p}-$ & - \\
\hline
\end{tabular}

needed to produce an efficient confinement of free carriers. However, due to the lattice mismatch (1.3\%) of this system, the InGaAs layer critical thickness must not be too thick so as to preserve the transport properties advantages of the pseudomorphic strained heterostructures [4]. Thus, the strained - layer AlGaAs/InGaAs HEMT derives its better performances from both the higher mobility value in the InGaAs than in the GaAs material and from the reduction of the DX related effects while maintaining a high electron gas density. According to these concepts, pseudomorphic HEMTs should provide less G-R noise components than conventional devices. To obtain some insight into the sources of the LF excess noise, its behaviour was analysed as a function of the gate and of the drain biases in the $90 \mathrm{~K}-300 \mathrm{~K}$ range. The evolution of the current noise spectra as a function of the temperature has allowed to identify deep levels responsible for parasitic effects in the HEMT.

\section{Description of the devices}

The devices under test are based on the AlGaAs/GaAs-buffer layer and AlGaAs/InGaAs/GaAs modulation doped heterostructures respectively for the conventional HEMTs (S-HEMTs) and for the pseudomorphic HEMTs (PM-HEMTs). Three types of conventional devices (A, B, C) are distinguished according to the nature of the buffer layer (Tab. I). An AlGaAs buffer is used to create an energy barrier in the conduction band and to reduce electron injection into the buffer, as it has been proposed by Morkoc [5]. The epitaxial growth process is a Vapor Phase Epitaxy using metallorganic sources (MOCVD). The Al molecular fraction of the n-doped AlGaAs layer deposited onto a 20-30 $\AA$ non-doped AlGaAs spacer is 0.28 . The $150 \AA$ InGaAs layer of the PM-HEMTs (D type) has been grown by Molecular Beam Epitaxy (MBE). The molefraction of In was minimized to 0.15 to reduce lattice mismatch at the heterointerface and the $\mathrm{Al}$ molefraction is 0.22 .

The double barrier quantum well structure (device $D$ ) presents two conduction band discontinuities : $\Delta E_{\mathrm{cl}}=0.30 \mathrm{eV}$ and $\Delta E_{\mathrm{c} 2}=0.12 \mathrm{eV}$ while the potential barrier energy of the single heterostructure is $0.22 \mathrm{eV}$ in the conventional FET as represented in Figure 1.

Identical masks were used to define the gate and ohmic cc.ntacts of all devices; the six gate fingers are $0.5 \mu \mathrm{m}$ long and $33 \mu \mathrm{m}$ wide. The ohmic contacts are deposited onto $\mathrm{a} \mathrm{n}^{+}-\mathrm{doped}$ GaAs cap layer $\left(1 \times 10^{18} \mathrm{~cm}^{-3} \leq N_{\mathrm{D}} \leq 2 \times 10^{18} \mathrm{~cm}^{-3}\right)$. 

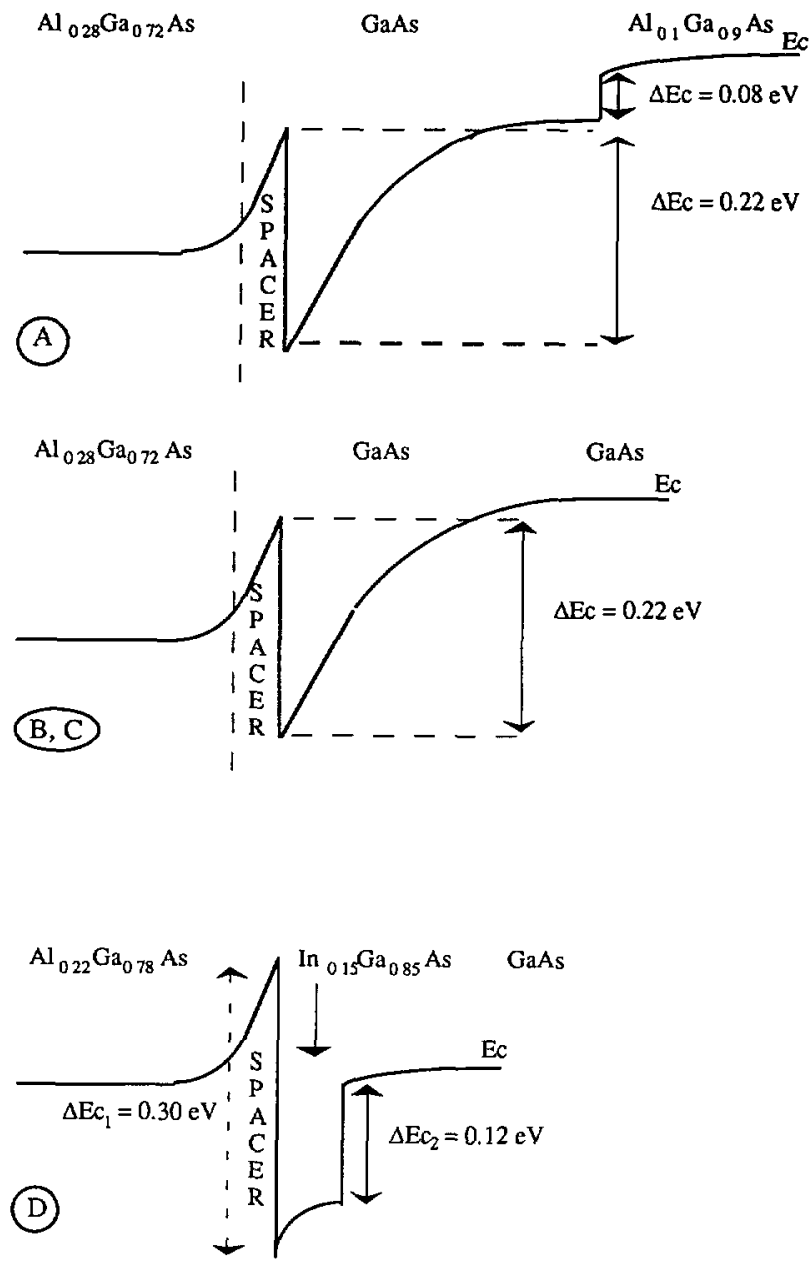

Fig. 1, - Conduction band diagram: A: AlGaAs/GaAs/AlGaAs HEMT; B, C: AlGaAs/GaAs/GaAs HEMT; D: AlGaAs/InGaAs/GaAs HEMT.

\section{Experimental results}

LF noise investigations were conducted to evaluate and compare the influence of the physical characteristics due to the heterostructure layers on the global quality of devices. The measurements were performed in the ohmic regime and in the frequency range: $1 \mathrm{~Hz}-100 \mathrm{kHz}$.

3.1. $1 / f$ Noise Analysis versus Drain Voltage. - The $1 / f$ noise spectra of all devices follow the relation (1):

$$
S_{i_{\mathrm{D}}}=\frac{\alpha_{\mathrm{H}}}{N} \frac{I_{\mathrm{ds}}^{2}}{f}
$$

where $N$ is the total number of free electrons in the channel. 


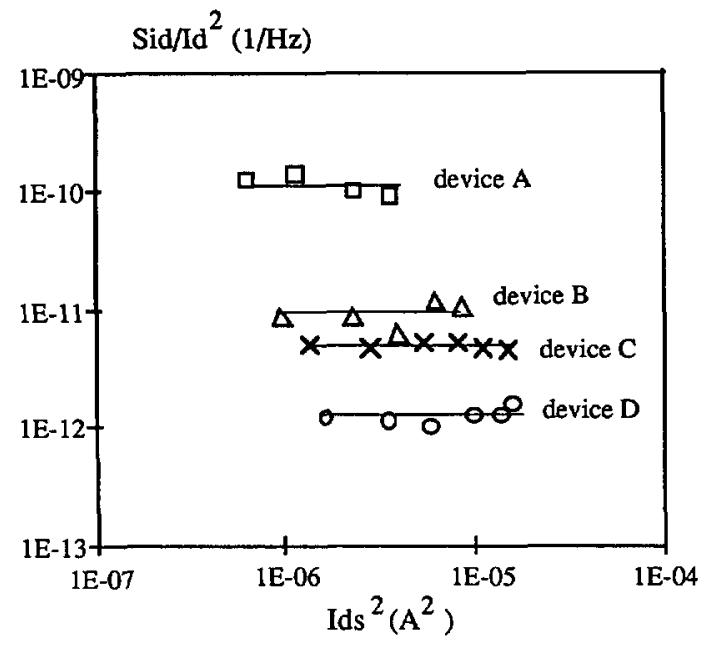

Fig. 2

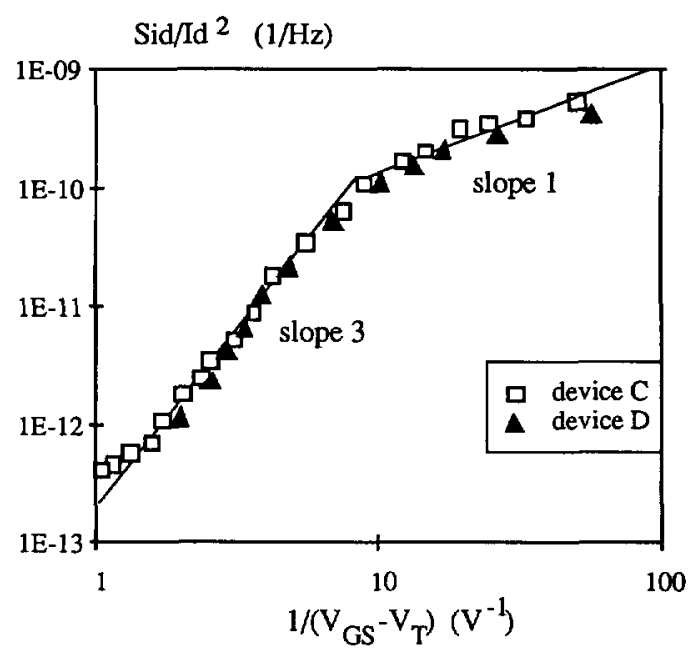

Fig. 3

Fig. 2. - Normalised current noise spectral intensity vs. the squared drain current in the ohmic regime at $f=10 \mathrm{~Hz}\left(V_{\mathrm{GS}}=0 \mathrm{~V}\right)$.

Fig. 3. - Evolution of the normalised drain current noise vs. the inverse of the relative gate voltage $\left(f=20 \mathrm{~Hz}-V_{\mathrm{DS}}=50 \mathrm{mV}\right)$.

As verified in Figure 2, the current noise spectral intensity normalised to the squared drain current $S_{{ }_{\mathrm{D}}} / I_{\mathrm{D}}^{2}$ remains independent of the drain bias in the ohmic regime (20 $\mathrm{mV} \leq V_{\mathrm{ds}} \leq 70$ $\mathrm{mV}$ ). At $f=10 \mathrm{~Hz}$, the values of the $\alpha_{\mathrm{H}} / N$ factor (where $\alpha_{\mathrm{H}}$ is the Hooge parameter) are respectively $1.1 \times 10^{-9}, 9.3 \times 10^{-11}$ and $4.7 \times 10^{-11}$ for $\mathrm{A}, \mathrm{B}$ and $\mathrm{C}$ devices. So, the $1 / f$ noise level is more important for $A$ devices than for $B$ and $C$ devices. Therefore, the residual dopant type of the GaAs buffer layer ( $p^{-}$type for $B$ devices and $n^{-}$type for $C$ devices) has no influence on the channel noise level of conventional devices.

Owing to the presence of the AlGaAs buffer layer in A devices which induces a band conduction offset of $0.08 \mathrm{eV}$ (Fig. 1, device A), the free electrons are shielded from the substrate traps. This suggests that the $1 / f$ noise of conventional devices in the ohmic regime is not issued from free carriers density fluctuations related to the injection of electrons into the substrate. The high $1 / f$ current noise level could originate from structural defects located at the $\mathrm{GaAs} / \mathrm{AlGaAs}$ buffer interface resulting from the technological process.

A value of $1.2 \times 10^{-11}$ is obtained for $\alpha_{\mathrm{H}} / N$ on PM-HEMT (device D), i.e about one or two orders of magnitude lower than for $\mathrm{A}, \mathrm{B}$ and $\mathrm{C}$ devices. This confirms the better $1 / f$ noise performance of PM-HEMTs.

3.2. $1 / f$ Excess Noise VaRiation versus Gate Bias. - In the following, a comparison is performed between the best conventional HEMT ( $\mathrm{C}$ device) and the PM-HEMT ( $\mathrm{D}$ device) performances. In Figure 3, the normalised drain noise spectral intensity is reported as a function of the inverse of the relative gate voltage $1 /\left(V_{\mathrm{GS}}-V_{\mathrm{T}}\right) . V_{\mathrm{T}}$ is the threshold voltage of the HEMT evaluated from noise measurements in the ohmic regime.

As previously reported for conventional HEMTs [6], the evolution of the PM-HEMT normalised drain current noise versus $1 /\left(V_{\mathrm{GS}}-V_{\mathrm{T}}\right)$ gives information on the origin of the $1 / f$ 
excess noise and presents three different regions.

The total drain noise in the ohmic regime can be written as:

$$
\begin{gathered}
\frac{S_{i_{\mathrm{D}}}}{I_{\mathrm{DS}}^{2}}=\frac{S_{R_{\mathrm{T}}}}{R_{\mathrm{T}}^{2}}=\frac{S_{R_{\mathrm{CH}}}+S_{R_{\mathrm{S}}}}{\left(R_{\mathrm{CH}}+R_{\mathrm{S}}\right)^{2}} \\
\frac{S_{\imath_{\mathrm{D}}}}{I_{\mathrm{DS}}^{2}}=\frac{1}{R_{\mathrm{T}}^{2}}\left[\frac{\alpha_{\mathrm{CH}} q \mu_{\mathrm{CH}}}{L_{\mathrm{G}}^{2}} R_{\mathrm{CH}}^{3}+\frac{\alpha_{\mathrm{S}} q \mu_{\mathrm{S}}}{\left(L-L_{\mathrm{G}}\right)^{2}} R_{\mathrm{S}}^{3}\right] \frac{1}{f}
\end{gathered}
$$

where $S_{R_{\mathrm{CH}}}$ is the intrinsic channel noise, $S_{R_{\mathrm{S}}}$ represents the noise contribution of the access zones (gate to drain or source series resistances), $L_{\mathrm{G}}$ the gate length and $L$ the source-drain distance. It is not trivial to separate the respective contributions of the series resistances and of the intrinsic channel to the current noise in the HEMT.

For values of $1 /\left(V_{\mathrm{GS}}-V_{\mathrm{T}}\right)$ higher than 2, the series resistance equivalent noise $S_{R_{\mathrm{S}}}$ can be neglected when compared to the intrinsic channel noise. The slope of the plot is 1 or 3 , depending upon the respective values of $R_{\mathrm{CH}}$ and $R_{\mathrm{S}}$.

In the slope 1 region, the total resistance $R_{\mathrm{T}}$ (between drain and source) is reduced to the intrinsic channel resistance $R_{\mathrm{CH}}$. Then, equation (3) becomes:

$$
\frac{S_{\imath_{\mathrm{D}}}}{I_{\mathrm{DS}}^{2}}=\frac{\alpha_{\mathrm{CH}} q d}{L_{\mathrm{G}} W \varepsilon} \frac{1}{\left(V_{\mathrm{GS}}-V_{\mathrm{T}}\right)} \frac{1}{f}
$$

using:

$$
R_{\mathrm{CH}}=\frac{L_{\mathrm{G}} d}{\mu_{\mathrm{CH}} W \varepsilon} \frac{1}{\left(V_{\mathrm{GS}}-V_{\mathrm{T}}\right)}
$$

where $W$ is the gate width, $d$ the thickness and $\varepsilon$ the dielectric permittivity of the AlGaAs layer. This relation is verified by experimental results (Fig. 3) and $\alpha_{\mathrm{CH}}$ appears to be independent of the gate bias in this region. An identical value of $3.8 \times 10^{-4}$ is obtained for $\mathrm{C}$ and $\mathrm{D}$ devices; from the respective $\alpha_{\mathrm{H}} / N$ factor values of $C$ and $D$ devices (cf Sect. 3.1), it is assessed that a higher number of free electrons is present in the intrinsic channel (2DEG) for PM-HEMT than for S-HEMT.

In the slope 3 region, the channel resistance $R_{\mathrm{CH}}$ is smaller in comparison with $R_{\mathrm{S}}$. Then, equation (3) gives:

$$
\frac{S_{I_{\mathrm{D}}}}{I_{\mathrm{DS}}^{2}}=\frac{\alpha_{\mathrm{CH}} q \mu_{\mathrm{CH}}}{L_{\mathrm{G}}^{2}} \frac{R_{\mathrm{CH}}^{3}}{R_{\mathrm{S}}^{2}} \frac{1}{f}
$$

The value of the slope results in this zone from the variations of $\frac{R_{\mathrm{CH}}^{3}}{R_{\mathrm{S}}^{2}}$ versus $1 /\left(V_{\mathrm{GS}}-V_{\mathrm{T}}\right)$. In Figure 4, a linear dependence of $R_{\mathrm{T}}^{2}$ on $1 /\left(V_{\mathrm{GS}}-V_{\mathrm{T}}\right)$ is observed which implies a dependence of $R_{\mathrm{S}}$ on $1 /\left(V_{\mathrm{GS}}-V_{\mathrm{T}}\right)$. It results that the theoretical expression (Eq. (5)) of $R_{\mathrm{CH}}$ is not verified in the slope 3 region.

For values of $1 /\left(V_{\mathrm{GS}}-V_{\mathrm{T}}\right)$ lower than 2 , the access resistance noise $S_{R_{\mathrm{a}}}$ is dominating. Then, the equation (3) is reduced to :

$$
\frac{S_{\mathrm{i}_{\mathrm{D}}}}{I_{\mathrm{DS}}^{2}}=\frac{\alpha_{\mathrm{s}} q \mu_{\mathrm{s}}}{\left(L-L_{\mathrm{G}}\right)^{2}} R_{\mathrm{s}} \frac{1}{f}
$$

As $S_{\imath_{\mathrm{D}}} / I_{\mathrm{D}}^{2}$ depends again on $1 /\left(V_{\mathrm{GS}}-V_{\mathrm{T}}\right)$ (Fig. 3), a variation of the series resistances value with $1 /\left(V_{G S}-V_{T}\right)$ should be assessed. In this $1 /\left(V_{G S}-V_{T}\right)$ range value, the Schottky gate diode enters the forward bias regime which reduces (due to the decrease of the $I_{\mathrm{D}}$ current) the measurements possibilities. 


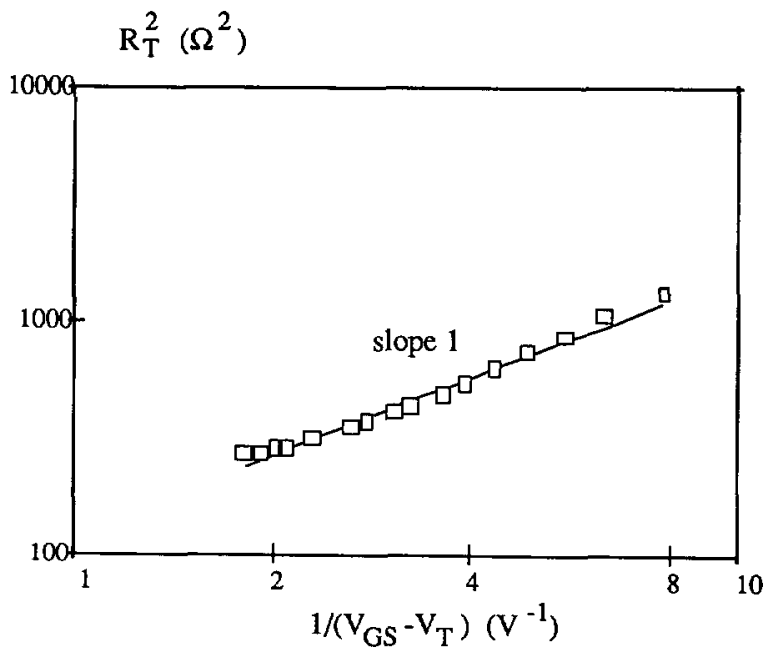

Fig. 4. - Total resistance $R_{\mathrm{T}}$ vs. the inverse of the relative gate voltage.

Sid $\left(A^{2} / \mathrm{Hz}\right)$

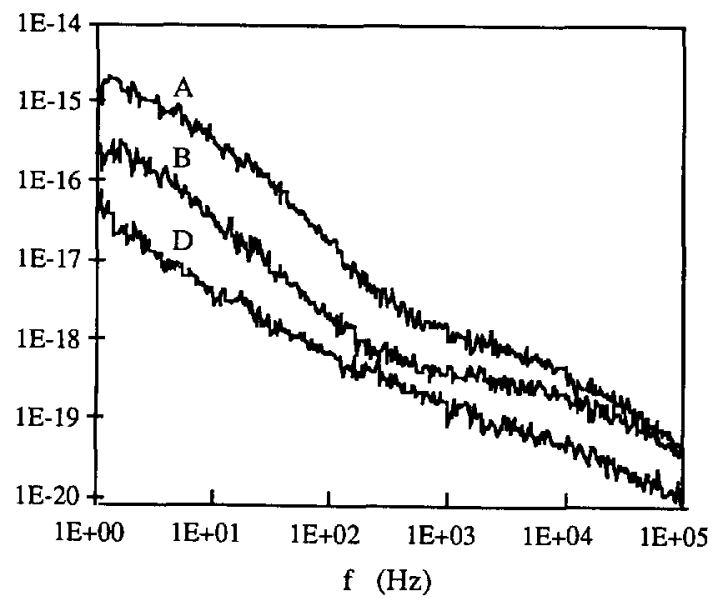

Fig. 5. - Comparison of the drain current noise spectra (measured at $I_{\mathrm{ds}}=1.9 \mathrm{~mA}$ ) for A, B and D devices.

3.3. G-R Noise versus Gate Bias. - As seen in Figure 5, the PM-HEMT current noise behavior shows a G-R component which seems less pre-eminent than in S-HEMT devices. This could originate from the lower Al molefraction of the n-AlGaAs in PM-HEMT. As already demonstrated by several authors [7,8], the pre-eminent G-R noise component which cut-off frequency is around $10 \mathrm{kHz}$ (at ambient temperature) is supposed to be related to the DX traps contribution in the conventional HEMTs if the Al molefraction is higher than 0.22 [9].

Drain current noise measurements on PM-HEMT for gate voltage between $-0.5 \mathrm{~V}$ and $0 \mathrm{~V}$ at fixed drain bias $\left(50 \mathrm{mV}\right.$ ) have been performed. For values of the gate bias $V_{\mathrm{Gs}}$ close to the threshold voltage of the device, the excess channel noise exhibits a $1 / f$ behaviour at room 


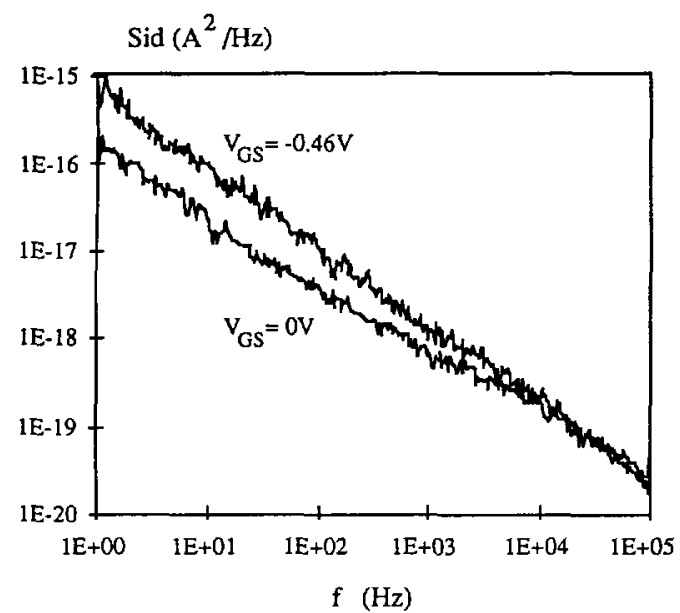

Fig. 6

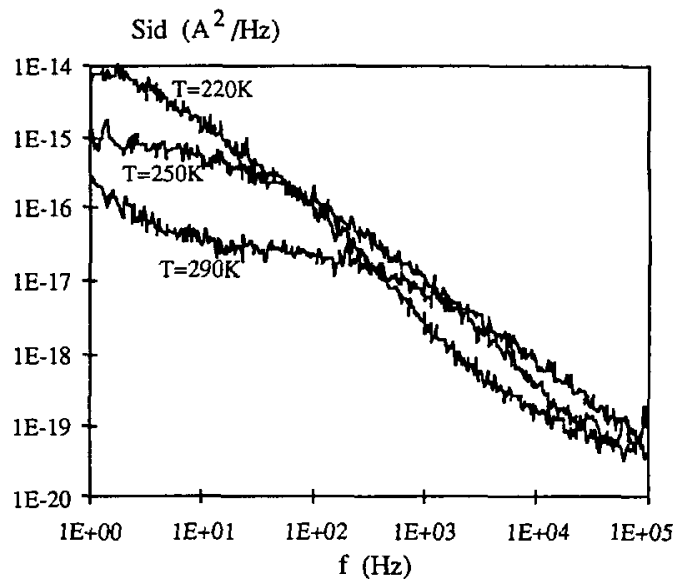

Fig. 7

Fig. 6. - Evolution of the PM-HEMTs G-R noise contributions as a function of the gate bias.

Fig. 7. - Evolution of the drain current noise spectral intensity as a function of temperature (for B device).

temperature. When increasing the gate bias, G-R noise contributions appear in the noise spectra (Fig. 6). This evolution is similar to that observed on conventional HEMTs [10].

3.4. G-R NoIse versus Temperature. - At cryogenic temperatures, the HEMTs were operated in the ohmic regime at a constant drain bias. For the temperature range $200 \mathrm{~K}$ $300 \mathrm{~K}$, the corner frequency of G-R contributions shifts towards the lower frequencies for B (Fig. 7), C and D devices.

The shift of the corner frequency $f_{c}$ versus temperature is drawn on the Arrhenius plot of $\log \left(T^{2} / f_{\mathrm{c}}\right)$ (Fig. 8). The activation energy $E_{\mathrm{a}}$ and the capture cross-section $\sigma$ are obtained from a least-squares linear regression. In Table II, $E_{\mathrm{a}}$ and $\sigma$ are reported for B, C and D devices. The values of these parameters clearly identify levels which are those of the generic DX center [3].

According to the proposition of Kugler [2], based on a spatially - dependent time constant $\tau$, the G-R current noise spectral intensity over the whole space charge region (SCR) is expressed as:

$$
S_{\imath_{\mathrm{D}}}=\frac{4 N_{\mathrm{T}} I_{\mathrm{D}}^{2} L W}{N^{2}} \int_{\mathrm{SCR}} \frac{\tau(x) f_{\mathrm{T}}(x)\left(1-f_{\mathrm{T}}(x)\right)}{1+(2 \pi f \tau(x))^{2}} \mathrm{~d} x
$$

where $I_{\mathrm{D}}$ is the gate current, $L$ and $W$ the gate dimensions, $\tau(x)$ the spatially-dependent time constant and $f_{\mathrm{T}}(x)\left(1-f_{\mathrm{T}}(x)\right)$ the probability in the traps occupancy.

On the assumption of a non-spatially dependent time constant $\tau$, the spectral intensity of the current noise is given from ( 8 ) by:

$$
S_{\imath_{\mathrm{D}}}=\frac{4 I_{\mathrm{D}}^{2} L W d}{N^{2}} \frac{\tau N_{\mathrm{T}} f_{\mathrm{T}}\left(1-f_{\mathrm{T}}\right)}{1+(2 \pi f \tau)^{2}}
$$




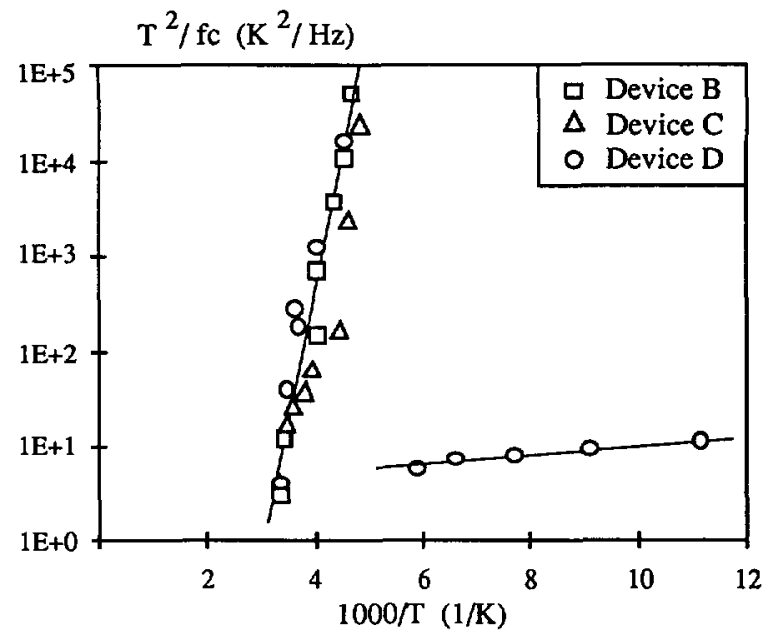

Fig. 8. - Arrhenius plot to identify : - the DX center in B, C and D devices; - the specific trap in PM-HEMTs.

Table II. - Characteristics of traps identified in $B, C$ et $D$ devices.

\begin{tabular}{|c|c|c|}
\hline Device type & $E_{\mathrm{a}} \pm 0.05(\mathrm{eV})$ & $\sigma\left(\mathrm{cm}^{2}\right)$ \\
\hline B & DX traps: 0.50 & $1.2 \times 10^{-15}$ \\
\hline C & DX traps: 0.40 & $5.3 \times 10^{-17}$ \\
\hline D & DX traps: 0.55 & $3.2 \times 10^{-14}$ \\
\hline D & specific level: & $1.3 \times 10^{-21}$ \\
\hline
\end{tabular}

where $d$ is the space charge region width (approximated to the AlGaAs active layer thickness). From equation (9) and the "plateau" level of the G-R components (measured at $I_{\mathrm{D}}=3.5 \mathrm{~mA}$ ), the effective traps density $N_{\mathrm{T}} f_{\mathrm{T}}\left(1-f_{\mathrm{T}}\right)$ is evaluated to $1 \times 10^{14} \mathrm{~cm}^{-3}$ and $4 \times 10^{13} \mathrm{~cm}^{-3}$ for $\mathrm{C}$ and $\mathrm{D}$ devices respectively.

For the PM-HEMT, another G-R noise contribution appears in the temperature range of $170 \mathrm{~K}$ to $90 \mathrm{~K}$. The activation energy $E_{\mathrm{a}}$ and the capture cross-section $\sigma$ of this specific level are reported in Table II.

In reference [11], a trap with an activation energy of $0.08 \mathrm{eV}$ has been reported in PMHEMTs in the temperature range of $250 \mathrm{~K}-320 \mathrm{~K}$ and its origin attributed to the InGaAs-GaAs interface. 


\section{Conclusions}

The LF drain current noise analysis of conventional and pseudomorphic HEMTs (issued from identical metallurgical processes) has been performed to evaluate the global quality of these devices through the $\alpha_{\mathrm{H}} / N$ factor. The lower PM-HEMT $\alpha_{\mathrm{H}} / N$ parameter value verifies that a better carrier confinement is achieved from the significant conduction band discontinuity at the AlGaAs/InGaAs interface and from the deep offset at the InGaAs/GaAs buffer. A higher sheet charge density is maintained in PM-HEMTs than in S-HEMTs but very similar intrinsic channel contributions to the LF noise current are observed through an identical value of the $\alpha_{\mathrm{CH}}$ parameter: $3.8 \times 10^{-4}$.

DX centers have been characterised in conventional and pseudomorphic HEMTs according to the G-R noise dependence on temperature. It has been verified that a low Al molefraction in the $\mathrm{n}-\mathrm{AlGaAs}$ layer implies a lower G-R noise level and therefore a weaker deep traps concentration. The detection and the characterisation of a shallow trap in PM-HEMTs through the G-R noise evolution versus temperature has been related to the AlGaAs/InGaAs interface structure.

\section{References}

[1] Audren P., Dumas J.M., Favennec M.P. and Mottet S., Etude des pièges dans les transistors à haute mobilité électronique sur GaAs à l'aide de la méthode dite de "relaxation isotherme". Corrélation avec les anomalies de fonctionnement, J. Phys. III, France 3 (1993) 185-206.

[2] Kugler S., Evaluation of the trap concentration in highly doped semiconductors from low frequency noise spectra, J. Appl. Phys. 66 (1989) 219-222.

[3] Kirtley J.R., Theis T.N., Mooney P.M. and Wright S.L., Noise spectroscopy of deep level (DX) centers in $\mathrm{GaAs}_{-} \mathrm{Al}_{x} \mathrm{Ga}_{1-x}$ As heterostructures, J. Appl. Phys. 63 (1988) 1541-1548.

[4] Ali F. and Gupta A., HEMTs and HBTs devices, Fabrication and Circuits (Artech House Ed., U.S.A., 1991) p. 106.

[5] Morkoc H., Kopp W.F., Drummond T.J., Su S.L., Thorne R.E. and Fisher R., Submicron gate $\mathrm{GaAs} / \mathrm{Al}_{0.3} \mathrm{Ga}_{0.7} \mathrm{As}$ MESFETs with extremely sharp interfaces $(40 \AA)$, IEEE Trans. Electron. Devices ED-29 (1982) 1013-1018.

[6] Peransin J.M., Vignaud P., Rigaud D. and Vandamme L.K.J., $1 / f$ noise in MODFETs at low drain bias, IEEE Trans. Electron. Devices ED-37 (1990) 2250-2253.

[7] Hofman F., Zijlstra R.J.J., Bettencourt de Freitas J.M. and Henning J.C.M., Generation- recombinaison noise in $\mathrm{Al}_{x} \mathrm{Ga}_{1-x}$ As, Sol. St. Elect. 34 (1991) 23-32.

[8] Labat N., Saysset N., Ouro Bodi D., Touboul A., Danto Y, Tedesco C., Paccagnella A. and Lanzieri C., Investigations on the origin of AlGaAs-GaAs HEMTs LF channel noise, Proc. ICNF, St Louis, USA (1993) pp. 264-267.

[9] Ali F. and Gupta A., HEMTs and HBTs devices, Fabrication and Circuits (Artech House Ed., U.S.A., 1991) p. 83.

[10] Labat N., Ouro Bodi D., Touboul A., Danto Y. and Durnas J.M., Low frequency noise analysis to detect the influence of deep levels in AlGaAs/GaAs HEMTs, QREI 8 (1992) 301-305.

[11] Plana R., Escotte L., Llopis O., Amine H., Parra T., Gayral M. and Graffeuil J., Noise in AlGaAs/InGaAs/GaAs pseudomorphic HEMTs from $10 \mathrm{~Hz}$ to $18 \mathrm{GHz}$, IEEE Trans. Electron. Devices ED-40 (1993) 852-858. 